\title{
Edukasi Program Posyandu dimasa Pandemi Covid-19 sebagai Upaya Membentuk Persepsi Masyarakat di Wilayah Kerja Posyandu Cempaka Kelurahan Kuin Selatan Kota Banjarmasin
}

\author{
Norfai $^{1}$, Eddy Rahman $^{2}$, Abdullah $^{3}$ \\ ${ }^{1,2,3}$ FakultasKesehatan Masyarakat Universitas Islam Kalimantan \\ (UNISKA)MAAB Banjarmasin \\ Email:norfai92@gmail.com
}

Submitted : 24/03/2021

Accepted: 16/04/2021

Published: 28/06/2021

\begin{abstract}
The purpose of this service activity is to increase public knowledge, especially mothers who have babies or children under five years (balita), about the posyandu program. Before starting counseling, a questionnaire was filled (pretest). Counseling uses power point media with the lecture, discussion and question and answer method, then after being given counseling, the same questionnaire was distributed again to be filled back (posttest), after the knowledge data before and after counseling had been obtained, then the data were analyzed using the Wilcoxon statistical test.Based on the results of community service activities in the work area of the Banjarmasin Kuin Selatan Village Cempaka Posyandu, it means that there is a significant difference in knowledge between before and after counseling using power point media, thus it can be concluded that the method of extension using power point media carried out in the work area of the Banjarmasin Kuin Selatan Village Cempaka Posyandu is able and successful in increasing the knowledge of mothers who have chldren under five years. It is recommended that the local public health service (puskesmas) can provide more intensive guidance and training to posyandu cadres, so that they can assist health workers in educating the public about health in general and information about the importance of posyandu and the activities at the posyandu itself as an effort to participate forming a positive perception of the posyandu.
\end{abstract}

Keywords: education, posyandu program, perception

\begin{abstract}
Abstrak
Tujuan dari kegiatan pengabdian ini adalah untuk meningkatkan pengetahuan masyarakat, khususnya ibu yang mempunyai bayi atau balita mengenai program posyandu. Sebelum memulai penyuluhan, dilakukan pengisian kuesioner (pretest). Penyuluhan menggunakan media power poin dengan metode ceramah, diskusi serta tanya jawab, kemudian setelah diberikan penyuluhan, maka dibagikan kembali kuesioner yang sama seperti sebelumnya untuk diisi kembali (posttest), setelah data pengetahuan sebelum dan sesudah penyuluhan sudah didapatkan, maka dilakukan analisis data menggunakan uji statistik wilcoxon. Berdasarkan hasil kegiatan pengabdian di wilayah kerja posyandu Cempaka Kelurahan Kuin Selatan kota Banjarmasin menunjukkan terdapat perbedaan pengetahuan yang bermakna antara sebelum dan sesudah penyuluhan menggunakan media power point, dengan demikian dapat disimpulkan bahwa metode penyuluhan menggunakan media power point yang dilakukan di wilayah kerja posyandu Cempaka Kelurahan Kuin Selatan kota Banjarmasin mampu dan berhasil meningkatkan pengetahuan ibu balita. Disarankan agar pihak puskesmas setempat dapat melakukan pembinaan dan pelatihan lebih itensif kepada kader posyandu, agar dapat membantu petugas kesehatan dalam rangka mengedukasi masyarakat mengenai kesehatan secara umum dan informasi mengenai pentingnya posyandu serta kegiatan-kegiatan yang ada di posyandu tersebut itu sendiri sebagai upaya dalam turut serta membentuk persepsi yang positif terhadap posyandu.
\end{abstract}

Kata Kunci: edukasi, program posyandu, persepsi 


\section{PENDAHULUAN}

Posyandu adalah salah satu bentuk Upaya Kesehatan Bersumber Daya Masyarakat (UKBM) yang dikelola dan diselenggarakan dari, oleh, untuk dan bersama masyarakat dalam penyelenggaraan pembangunan kesehatan guna memberdayakan masyarakat dan memberikan kemudahan kepada masyarakat dalam memperoleh pelayanan kesehatan dasar Upaya peningkatan peran dan fungsi Posyandu bukan semata-mata tanggungjawab pemerintah saja, namun semua komponen yang ada di masyarakat, termasuk kader. Peran kader dalam penyelenggaraan Posyandu sangat besar karena selain sebagai pemberi informasi kesehatan kepada masyarakat juga sebagai penggerak masyarakat untuk datang ke Posyandu dan melaksanakan perilaku hidup bersih dan sehat (Kemenkes RI, 2012).

Pelayanan kesehatan posyandu meliputi system pelayanan lima meja, yaitu meliputi pendaftaran, pencatatan bayi, pencatatan balita, pencatatan ibu hamil, pencatatan ibu menyusui dan pencatatan usia subur. Meja kedua meliputi, penimbangan balita, penimbangan ibu hamil. Meja ketiga meliputi, pengisian KMS. Meja keempat meliputi mengenal balita berdasarkan berat badan, pemberian makanan tambahan, pemberian oralit, vitamin dosis tinggi, pemberian tablet besi pada ibu hamil dengan risiko tinggi, pelayanan $\mathrm{kb}$ serta pemberian kondom serta pil. Meja kelima meliputi pelayanan KIA, KB, imunisasi dan pengobatan, serta pelayanan lain sesuai kebutuhan setempat. Kepuasan ibu-ibu balita terhadap pelayanan kesehatan posyandu akan timbul apabila pelayanan yang diberikan oleh petugas kesehatan posyandu sudah sesuai system lima meja, pelayanan tersebut dipengaruhi oleh factor eksternal dan internal (Rosita, 2017).
Cakupan penimbangan balita di Posyandu (D/S) merupakan indikator yang berkaitan dengan cakupan pelayanan gizi pada balita, cakupan pelayanan kesehatan dasar khusunya imunisasi serta prevalensi gizi kurang. Semakin tinggi cakupan D/S, semakin tinggi cakupan vitamin A, semakin tinggi cakupan imunisasi dan semakin rendah prevalensi gizi kurang. Program posyandu akan bermanfaat jika balita berkunjung ke posyandu secara teratur. Keteraturan berkunjung ke Posyandu Sangat diperlukan partisipasi ibu untuk membawa balitanya berkunjung ke Posyandu (Kemenkes RI, 2012).

Salah satu upaya untuk mengurangi angka kesakitan dan kematian balita adalah dengan melakukan pemeliharaan kesehatannya. Pemeliharaan kesehatan anak balita dititik beratkan kepada upaya pencegahan dan peningkatan kesehatan serta pengobatan dan rehabilitasi yang dapat dilakukan di Puskesmas, Puskesmas Pembantu, Polindes dan di Posyandu, karena Posyandu merupakan tempat yang paling cocok untuk memberikan pelayanan kesehatan pada balita secara menyeluruh dan terpadu (Nain, 2008).

Membawa balita ke Posyandu akan mendapatkan manfaat yaitu anak mendapatkan kesehatan ke arah yang lebih baik, mendapatkan kemudahan pelayanan disatu kesempatan dalam satu tempat sekaligus, dapat menghindari pemborosan waktu, tingkat partisipasi masyarakat mencapai target yang diharapkan dan cakupan pelayanan dapat diperluas sehingga dapat mempercepat terwujudnya peningkatan derajat kesehatan balita. Kunjungan balita di Posyandu berkaitan dengan peran Ibu sebagai orang yang paling bertanggung jawab terhadap kesehatan balitanya, karena balita sangat bergantung dengan Ibunya. Kunjungan Ibu dengan membawa balita ke Posyandu karena adanya motif tertentu misalnya agar anaknya mendapatkan pelayanan kesehatan yang 
maksimal. Untuk itu, motivasi Ibu dalam pemanfaatan Posyandu balita mempunyai andil yang besar dalam meningkatkan kesehatan balita (Uphoff, 2002).

Kunjungan balita di Posyandu berkaitan dengan peran ibu sebagai orang yang paling bertanggungjawab terhadap kesehatan balita, karena balita sangat bergantung pada ibu. Alasan utama ibu membawa balita ke Posyandu karena ingin anak mendapatkan pelayanan kesehatan yang maksimal. Oleh karena itu, motivasi ibu dalam pemanfaatan Posyandu balita mempunyai andil yang besar dalam meningkatkan kesehatan balitanya (Farida, 2012 dalam Wardani, dkk., 2015).

Persepsi warga masyarakat terhadapkegiatan program tertentu merupakan landasan atau dasar utama bagi timbulnya kesediaan untuk ikut terlibat dan berperan secara aktif dalam setiap kegiatan programtersebut. Makna positif atau negatif sebagaihasil persepsi seseorang terhadap program akan menjadi pendorong atau penghambat baginya untuk berperan dalam kegiatannya (Davidoff, 1988 dalam Wiratmoko, 2006).

Berbagai hal yang terjadi dan menjadi pengalaman yang kurang menyenangkan sering mengakibatkan warga masyarakat kurang bersikap terbuka untuk secara jujur menyatakan persepsi dan pandangannya tentang suatu program kegiatan yang secara resmi diselenggarakan oleh pemerintah. Karena sering dilandasi oleh persepsi yang kurang positif maka keterlibatan yang ada sering merupakan partisipasi semu. Keadaan demikian itu bila terjadi, sering membawa akibat kurang lancarnya kegiatan sesuai dengan rencana sehingga menyulitkan usaha pencapaian tujuan program secara utuh dan mantap (Sutopo, 1996 dalam Wiratmoko, 2006).

Selama ini banyak program pemerintah dalam usaha pengembangan masyarakat telah dirancang dan diputuskan hanyaberdasarkan konsep, dan pertimbangan dariatas (top down), tanpa memperhatikan kekhususan latar belakang sosial, ekonomi, dan budayanya, yang sangat memungkinkan terjadinya perbedaan persepsi antarwarga masyarakat terhadapnya. Akibatnya banyak program menghadapi kendala dalam pelaksanaannya, terutama dalam mengembangkan partisipasi aktif masyarakat sebagai komponen utama dalam mencapai keberhasilan suatu program (Wiratmoko, 2006).

Permasalahan yang mendasar yaitu belum adanya pemahaman yang komprehensif dari masyarakat mengenai program posyandu serta tujuan dari keberadaan posyandu di tengah-tengah masyarakat, dimana persepsi atau sudut pandang masyarakat mengenai posyandu masih sempit atau terbatas, dimana pandangan masyarakat selama ini mengenai posyandu yang sempit yaitu kegiatan rutin yang diadakan sebulan sekali dalam rangka penimbangan bayi dan balita, padahal keberadaan posyandu ditengah-tengah masyarakat dalam upaya peningkatan status gizi masyarakat serta dalam upaya kesehatan ibu dan anak, selain itu yang tidak kalah penting, posyandu merupakan sarana kesehatan yang efektif dalam upaya percepatan penurunan kasus stunting pada balita, karena pada dasarnya keberhasilan dalam penyelenggaraan posyandu, tidak terlepas dari dukungan berbagai pihak, bukan hanya sekedar partisipasi masyarakat, akan tetapi diperlukan kerjasama dengan berbagai sector terkait seperti tenaga kesehatan, kader posyandu dan stakeholder.Berdasarkan uraian data narasi diatas, maka perlunya dilakukan pengabdian kepada masyarakat mengenai "Edukasi Program Posyandu dimasa Pandemi Covid-19 sebagai Upaya Membentuk Persepsi Masyarakat di Posyandu Cempaka RT. 9 Kelurahan Kuin Selatan Kota Banjarmasin". 


\section{TARGET DAN LUARAN}

Target dalam pengabdian ini adalah meningkatkan pengetahuan ibu balita mengenai kegiatan-kegiatan posyandu sedangkan luarannya adalah publish ke jurnal pengabdian masyarakat.

\section{METODEPELAKSANAAN}

Mekanisme sebelum pelaksanaan penyuluhan terdiri dari tahap persiapan yaitu penyusunan preplanning, kontrak waktu\&menyepakati tempat penyuluhan serta mempersiapan media penyuluhan. Metode penyuluhan yang dilaksanakan yaitu dengan menggunakan media power poin dalam penyampaian materi mengenai "Edukasi program Posyandu", akan tetapi sebelum memulai penyuluhan, dilakukan kegiatan pretest yaitu pengisian kuesioner untuk mengukur atau mengetahui sejauh mana pengetahuan mengenai program Posyandu.

Proses penyuluhan yang dilaksanakan dengan metode yaitu metode ceramah, metode diskusiserta proses tanya jawab, kemudian setelah diberikan penyuluhan, maka dilakukan posttest yaitu dibagikan kembali kuesioner tersebut yang sama seperti sebelumnya untuk diisi kembali, setelah data pengetahuan sebelum dan sesudah penyuluhan sudah didapatkan, maka dilakukan uji statistik untuk mengetahui keefektifan metode penyuluhan yang telah disampaikan.

\section{HASIL DANPEMBAHASAN}

Pelaksanaan Kegiatan pengabdian kepada masyarakat dirincikan sebagai berikut :Jenis Kegiatan : Penyuluhan, Lokasi : Wilayah Kerja posyandu Cempaka Kelurahan Kuin Selatan Kota Banjarmasin, Materi : "Edukasi Program Posyandu".
Tabel 1.Hasil Pengetahuan Sebelum dan Sesudah Penyuluhan

\begin{tabular}{|c|c|c|c|}
\hline No. & Variabel & $\mathbf{n}$ & $\%$ \\
\hline \multirow[t]{7}{*}{1.} & Pengetahuan & & \\
\hline & (Sebelum & 3 & 20,0 \\
\hline & Penyuluhan) & 7 & 46,7 \\
\hline & Baik & 5 & 33,3 \\
\hline & Cukup & & \\
\hline & Kurang & & \\
\hline & Jumlah & 15 & 100 \\
\hline \multirow[t]{6}{*}{2.} & Pengetahuan & & \\
\hline & (Sesudah & 12 & 80 \\
\hline & Penyuluhan) & 3 & 20 \\
\hline & Baik & & \\
\hline & Cukup & & \\
\hline & Jumlah & 15 & 100 \\
\hline
\end{tabular}

Tabel 2.Hasil Analisis Uji Wilcoxon

\begin{tabular}{|c|c|c|c|c|}
\hline $\begin{array}{ll}\text { Sebelum dan } \\
\text { Sesudah } \\
\text { Perlakuan }\end{array}$ & $\mathrm{n}$ & $\begin{array}{l}\text { Median } \\
\text { (Minimu } \\
\text { m- } \\
\text { Maksim } \\
\text { um) }\end{array}$ & $\begin{array}{c}\text { Mea } \\
\mathrm{n}\end{array}$ & $\begin{array}{c}p- \\
\text { valu } \\
e\end{array}$ \\
\hline $\begin{array}{l}\text { Pengetahuan } \\
\text { Sebelum } \\
\text { Penyuluhan(Pre } \\
\text { test) } \\
\text { Pengetahuan } \\
\text { Sesudah } \\
\text { Penyuluhan(Po } \\
\text { sttest) }\end{array}$ & $\begin{array}{l}1 \\
5\end{array}$ & $\begin{array}{c}17,00 \\
(12-19)\end{array}$ & $\begin{array}{l}11 \\
67\end{array}$ & $\begin{array}{l}0,0 \\
01\end{array}$ \\
\hline
\end{tabular}

Berdasarkan tabel 2 diatas menunjukkan bahwa $p$-value $(0,001)<\alpha$ $(0,05)$ yang artinya secara statistik terdapat perbedaan pengetahuan yang bermakna antara sebelum dan sesudah penyuluhan menggunakan media power point, dengan demikian dapat disimpulkan bahwa metode penyuluhan menggunakan media power point yang dilakukan di wilayah kerja Posyandu Cempaka mampu dan berhasil meningkatkan pengetahuan ibu balita mengenai "Program Posyandu".

Berdasarkan hasil pretest didapatkan bahwa pengetahuan ibu mengenai program posyandu masih belum memenuhi secara utuh, terlihat dari 20 pernyataan, pernyataan 
nomor 3 mengenai pelayanan untuk bayi dan balita merupakan kegiatan utama Posyandu Kesehatan Ibu dan Anak (KIA), pernyataan nomor 14 mengenai Pelayanan kesehatan berupa penimbangan berat badan bayi atau balita, penentuan status pertumbuhan dan penyuluhan atau konseling merupakan bagian dari kegiatan utama dalam rangka memberikan pelayanan kepada bayi dan balita dan pernyataan nomor 16 mengenai salah satu kegiatan utama yang diselenggarakan posyandu adalah pelayanan imunisasi pada bayi.

Hasil pretest tersebut membuktikan bahwa seluruh ibu balita yang berjumlah 15 orang tersebut menjawab mengetahui kegiatan tersebut, dimana kegiatan tersebut merupakan kegiatan yang berfokus pada bayi atau balita, yang berarti bahwa ibu balita belum sepenuhnya mengetahui secara utuh mengenai program posyandu, dimana pemahaman mengenai program posyandu yang identik dengan kegiatan bayi atau balita perlu dirubah yaitu salah satunya dengan cara memberikan edukasi kepada ibu bayi atau ibu balita, agar ibu bayi atau balita tersebut memahami secara utuh program posyandu, dimana keberadaan posyandu berada ditengah-tengah masyarakat, akan tetapi hal tersebut dalam berjalan dengan baik, apabila semua sektor terkait ikut berperan aktif, seperti keaktifan kader dalam memberikan ajakan dan motivasi kepada ibu bayi dan balita agar berkunjung ke posyandu, selain itu perlu adanya pelatihan kader tersebut dalam rangka meningkatkan kualitas kader tersebut dan yang tidak kalah penting adalah perlu adanya insentif yang memadai bagi kader tersebut dalam rangka memberikan motivasi pada kader yang mengelola posyandu tersebut.

Petugas kesehatan di puskesmas pun turut serta dalam membina kader tersebut, dengan cara memberikan pelatihan dan edukasi, dimana informasi yang telah didapatkan dari petugas kesehatan di puskesmas tersebut dapat disampaikan kembali oleh kader tersebut yang terbentuk dalam kegiatan penyuluhan, karena kader merupakan orang yang dekat dengan masyarakat, khususnya ibu bayi atau balita tersebut.

Berdasarkan hasil penelitian yang dilakukan oleh Fatimah, dkk (2019) menunjukkan bahwaterdapat hubungan antara keaktifan kader dengan kunjunngan Posyandu dengan $p$-value $=0,013$. Pada dasarnya keberhasilan Posyandu tidak lepas dari perannya kader dalam mengelola Posyandu di wilayahnya masing-masing. Oleh sebab itu perlunya perhatian yang khusus kepada kader posyandu tersebut seperti melakukan pembinaan dan pelatihan terhadap kader tersebut, agar kader tersebut dapat secara mandiri memberikan edukasi atau penyuluhan kepada masyarakat atau khususnya kepada ibu bayi dan balita, sejalan dengan hasil prestest dan posttest yang menunjukkan bahwa adanya perubahan pengetahuan mengenai program posyandu antara sebelum dan sesudah penyuluhan.

Berdasarkan hasil pretest dan posttest membuktikan bahwa pemberian informasi mengenai program posyandu kepada ibu bayi atau balita berupa penyuluhan dapat meningkatkan pengetahuan ibu bayi atau ibu balita, dimana dengan adanya pengetahuan dan pemahaman mengenai program posyandu diharapkan dapat meningkatkan kunjungan ibu bayi atau ibu balita ke posyandu minimal 8 kali kunjungan dalam setahun dalam rangka memudahkan petugas kesehatan untuk mengetahui gambaran kesehatan masyarakat dan memantau kesehatan yang berada wilayah kerjanya serta sebagai dasar bahan evaluasi untuk kegiatan selanjutnya.

Secara teori menyatakan bahwa perilaku yang didasari pengetahuan akan lebih langgeng dari pada perilaku yang tidak didasari oleh pengetahuan, oleh sebab itu edukasi atau penyuluhan itu penting dalam membentuk persepsi seseorang, 
dimana persepsi yang positif akan cenderung mendorong seseorang untuk melakukan sebuah tindakan atau perilaku.
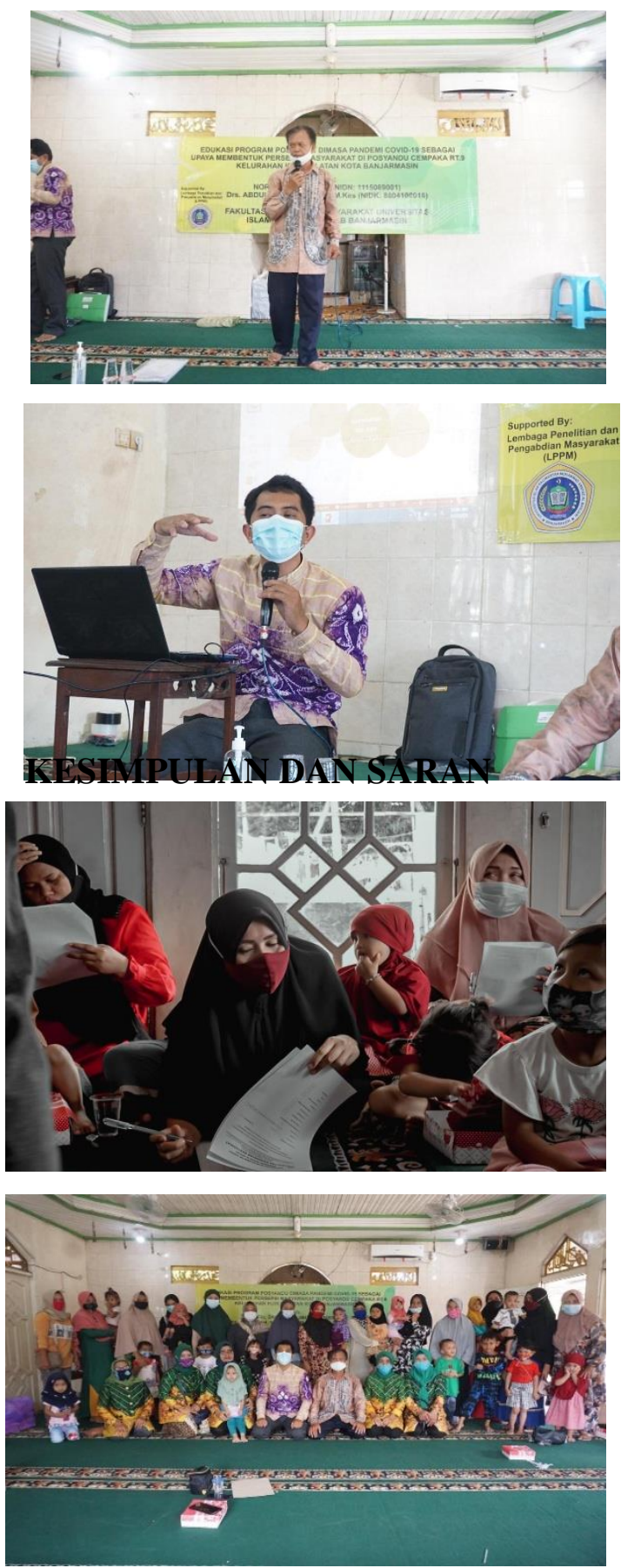

Gambar 1,2,3,4. Kegiatan edukasi

\section{KESIMPULAN DAN SARAN}

1. Kesimpulan

Berdasarkan hasil kegiatan pengabdian di wilayah kerja posyandu
Cempaka Kelurahan Kuin Selatan kota Banjarmasin menunjukkan terdapat perbedaan pengetahuan yang bermakna antara sebelum dan sesudah penyuluhan menggunakan media power point, dengan demikian dapat disimpulkan bahwa metode penyuluhan menggunakan media power point yang dilakukan di wilayah kerja posyandu Cempaka Kelurahan Kuin Selatan kota Banjarmasin mampu dan berhasil meningkatkan pengetahuan ibu balita mengenai program posyandu.

\section{Saran}

Disarankan agar pihak puskesmas setempat dapat melakukan pembinaan dan pelatihan lebih itensif kepada kader posyandu, agar dapat membantu petugas kesehatan dalam rangka mengedukasi masyarakat mengenai kesehatan secara umum dan informasi mengenai pentingnya posyandu serta kegiatan-kegiatan yang ada di posyandu tersebut itu sendiri sebagai upaya turut serta membentuk persepsi yang positif terhadap posyandu.

\section{UCAPAN TERIMA KASIH}

Penulis mengucapkan terima kasih kepada Lembaga Penelitian dan Pengabdian pada Masyarakat (LP2M) Universitas Islam Kalimantan Muhammad Arsyad Al Banjari Banjarmasindan Kepala Puskesmas Kuin Raya Kota Banjarmasin yang telah memberikan izin untuk melaksanakan kegiatan pengabdian masyarakat serta seluruh kader Posyandu Cempaka Kelurahan Kuin Selatan Kota Banjarmasin yang telah membantu dalam kegiatan Pengabdian Masyarakat ini.

\section{DAFTAR PUSTAKA}

Fatimah, Sari., Nislawaty., Hastuty, Milda., 2019. Jurnal Doppler. Hubungan Keaktifan Kader dengan Kunjungan Posyandu di Desa Rumbio UPTD Puskesmas Kampar Tahun 2019. Vol. 3, No. 2. [Online]. https://journal.universitaspahlawan.a c.id/index.php/doppler/article/view/ 
430. [diakses tanggal 23 Maret Uphoff, 2002. Program-program 2021].

Posyandu, Bagian I. Jakarta.

Kemenkes RI, Pusat Promosi Kesehatan, Wardani, Dian Palupi Kusuma, Sari, Sheizi 2012. Buku Saku Posyandu : Ayo ke Posyandu Setiap Bulan, Posyandu menjaga Anak dan ibu Tetap sehat. [Online].http://www.depkes.go.id/re sources/download/promosikesehatan /buku-saku-posyandu.pdf. [diakses tanggal 3 Desember 2020].

Nain, U., 2008. Posyandu : Upaya Kesehatan Berbasis Masyarakat. Yogyakarta:Kareso.

Rosita, Ani., 2017. Jurnal Kesehatan : Warta Bhakti Husada Mulia. Hubungan Antara Kinerja Petugas Kesehatan Posyandu Dengan Tingkat Kepuasan Ibu Balita Pengguna Posyandu Di Pacitan. Vol. 4, No. 2. [Online]. http://jurnal.bhmm.ac.id/index.php/j Prista dan Nurhidayah, Ikeu., 2015. Jurnal Keperawatan Padjadjaran. Hubungan Persepsi dengan Perilaku Ibu Membawa Balita ke Posyandu. Vol. 3, No. 1 April. [Online].

http://jkp.fkep.unpad.ac.id/index.ph p/jkp/article/view/93. [diakses tanggal3 Desember 2020].

Wiratmoko, Dheny., 2006. Pelita-Jurnal Penelitian Mahasiswa UNY. Persepsi dan Partisipasi Masyarakat terhadap Program Posyandu. Vol. I, No. 2 Mei 2006.[Online].https://journal.uny.ac. id/index.php/pelita/article/view/433 2/3753. [diakses tanggal 4 Desember 2020]. urkes/article/view/65. [diakses tanggal 3 Desember 2020]. 